\title{
POLYPEPTIDE COMPOSITION OF THYLAKOIDS FROM VIRIDIS AND XANTHA MUTANTS IN BARLEY
}

\author{
by \\ O. MACHOLD \\ Zentralinstitut für Genetik und Kulturpflanzenforschung \\ der A kademie der Wissenschaften der DDR, Gatersleben, GDR \\ G. HØYER-HANSEN \\ Department of Physiology, Carisberg Laboratory \\ Gamle Carlsberg Vej 10 - DK-2500 Copenhagen, Valby \\ 1 Recipient of a Danish State Scholarship 1975 for stay at the Institute of Genetics, \\ University of Copenhagen, where this work was performed
}

Key words: chlorophyll-protein complexes, chloroplast membranes, SDS-gel electrophoresis, photosystems, reaction centers

The chloroplast membrane proteins from four recessive nuclear gene mutants of barley were studied with sodium dodecyl sulfate gel electrophoresis. The protein patterns of two mutants, $x a n t h a-b^{12}$ and viridis-zd $d^{69}$, consist of a summation of the polypeptides present in the chloroplast and etioplast membranes of the wild type. The pattern of viridis- $\mathrm{c}^{12}$, a mutant deficient in photosystem II activity was lacking two bands, one of which is considered to be a component of the reaction center of photosystem II. The pattern of viridis- $k^{23}$ lacked three chloroplast specific bands, two of which are components of chlorophyll-protein complex II. The results are discussed in relation to previously established functional and structural characteristics of the mutant plastids.

\section{INTRODUCTION}

A survey of chlorophyll deficient seedling mutants in barley for alterations in the electrophoretic patterns of the chloroplast thylakoid proteins was carried out by N. C. NiELSEN $(6,13$, 14). Among the recessive nuclear gene mutants
(20) studied by solubilization of their plastid membranes with phenol-acetic acid-urea two groups could be distinguished. Mutants with leaky blocks in chlorophyll synthesis and therefore limited capacities to form grana had reduced amounts of a membrane protein band 
designated as J. Mutants with a tendency for stacking of thylakoids into giant grana and deficient in stroma thylakoids were deficient in the high molecular weight chloroplast membrane protein B.

In continuation of studies on the characterization of thylakoid proteins from barley mutants using membrane solubilization with sodium dodecyl sulfate (SDS) (12) and various conditions for electrophoresis (8) we report here on the thylakoid membrane pattern of four lethal nuclear gene mutants. Two of these are representative for the above mentioned two groups, mutant $x a n t h a-b^{12}$ producing giant grana and mutant viridis- $k^{23}$ (like xantha- $l^{35}$ ) being defective in the conversion of $\mathrm{Mg}$-protoporphyrin to protochlorophyllide (7). The other two mutants, viridis- $c^{12}$ and viridis- $z d^{69}$, are devoid of light induced $\mathrm{CO}_{2}$ fixation and oxygen evolution, although the mutant seedlings contain as much as 20 per cent of the amount of chlorophyll present in wild-type seedlings $(7,9)$.

Chloroplast preparations of mutant viridis- $c^{12}$ lack significant photosystem II actitity but could display photosystem I activity reaching one-third of wild-type rates $(14,17)$. HENNINGSEN (personal communication) found chloroplast preparations of viridis- $z d^{69}$ lacking in photosystem II actitity but active in a photosystem I dependent reaction with rates surpassing those of viridis- $c^{12}$.

\section{MATERIAL AND METHODS}

Wild-type (Hordeum vulgare c.v. Svalöf's Bonus) and mutant barley seedlings were grown on tap water moistened vermiculite for 7 days at $20^{\circ} \mathrm{C}$ at constant illumination ( 1500 lux $)$. The leaves were harvested just prior to homogenization and treated according to the flow sheet on the next page.

Electrophoresis was performed as described by HøYER-HANSEN, MACHOLD and KAHN (8) for the uniform gel system.

\section{RESULTS}

Chlorophyll contained in SDS micelles moved as a band near the front during electrophoresis of the pigment-containing, SDS-solubilized plastid membranes from all four mutants. The green band of chlorophyll-protein complex II (CP II) was visible for the membrane preparations of $x a n-b^{12}$ and $v i r-z d^{69}$, whereas a band corresponding to chlorophyll-protein complex I (CP I) could not be discerned. The preparation of vir- $k^{23}$ yielded no CP II band but a weak CP I band was visible at the beginning of the electrophoretic run and disappeared as electrophoresis proceeded. Mutant $v i r-c^{12}$ preparations gave neither CP I nor CP II bands.

The polypeptide pattern obtained after separation of acetone extracted and chemically reduced membrane proteins from the thylakoids of the four mutants is presented in Figure 1 together with the patterns from wild-type chloroplasts and wild-type etioplasts on either side. Aggregated polypeptides were found at the top of the gel with both wild-type and mutant membrane preparations. Such aggregates form upon removal of pigments from CP I $(4,11)$ and it is therefore possible that all four mutant membranes as well as those of the etioplasts (cf.8) contain the apoprotein of CP I. In Figure 2 the top portion of electrophoretograms from SDS-solubilized but not pigment extracted membrane preparations after staining with Coomassie blue are given. Only the wild-type membranes yielded a distinct CP I band corroborating the above mentioned observations of chlorophyll containing bands. The etioplasts and mutant plastids yielded aggregates not visible in the wild-type. Band I with an apparent molecular weight of 69,400 dalton representing the apoprotein of CP I $(4,8,11)$ is present in chloroplast membranes of the wild-type but absent in those of etioplasts. It is present but less intense in mutants $x a n-b^{12}, v i r-k^{23}$ and vir-zd $d^{69}$, and only represented by a very weak band in vir$c^{12}$ (Figs. 1,2).

The two bands $E$ and $F(60,600$ and 56,500 daltons respectively) ascribed to two subunits of the coupling factor $(11,21)$ are present in the membranes of the four mutants. Their intensity

\footnotetext{
Abbreviations: SDS - sodium dodecyl sulfate, CPI - chlorophyll-protein complex I, CPII - chlorophyll-protein complex II
} 
20-25 g leaves

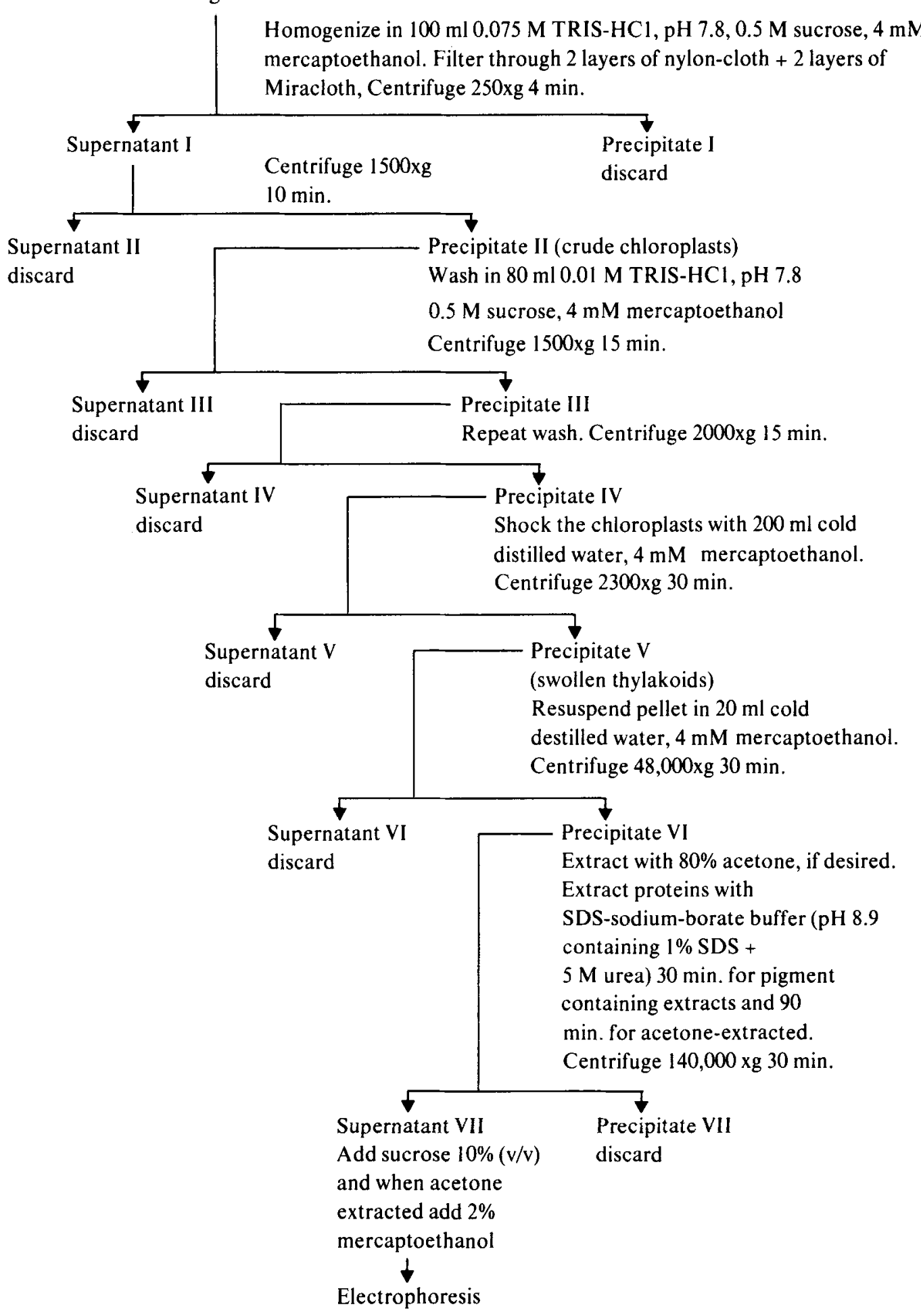

relative to the other bands varies being highest in the pattern of vir- $k^{23}$ (Fig. 1).

A comparison of the band pattern for polypep- tides with an electrophoretic mobility higher than the coupling factor subunits $E$ and $F$ reveals drastic differences between the chloro- 


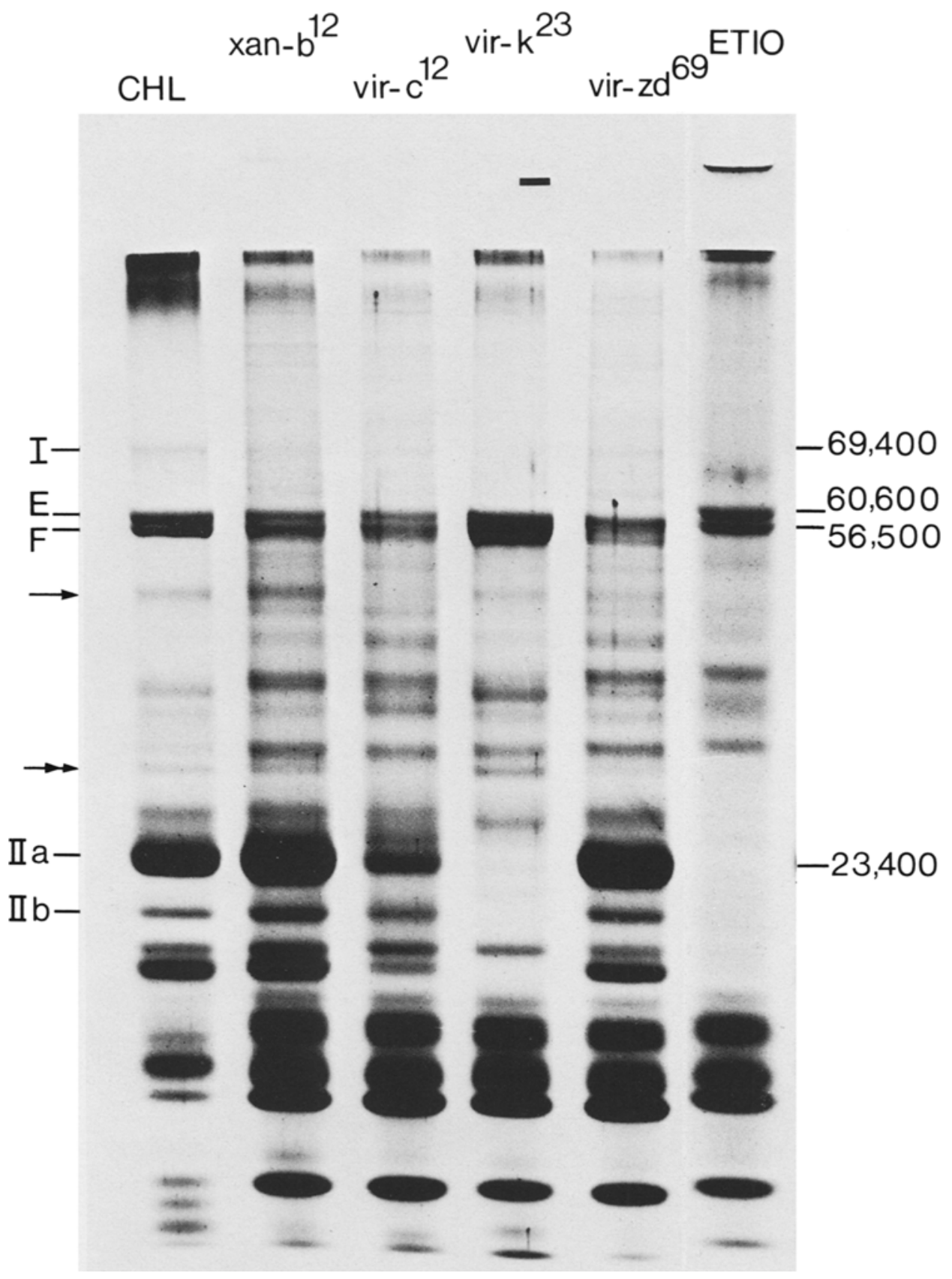

Figure 1. Electrophoretic separation of membrane proteins from wild-type chloroplasts, wild-type etioplasts and plastids of the mutants xantha- $\mathrm{b}^{12}$, viridis- $\mathrm{c}^{12}$, viridis- $\mathrm{k}^{23}$ and viridis- $\mathrm{zd}^{69}$. Membrane were extracted with acetone prior to SDS-solubilization and reduction with mercaptoethanol. Electrophoresis was carried out with the uniform gel system.

plast and etioplast internal membranes. These have been described in (8) and the major band differences are diagramed in Figure 3, which is directly comparable to Figure 1 . A band by band comparision reveals the pattern of $x a n-b^{12}$ and vir-z $d^{69}$ to be a summation of the band pat- 


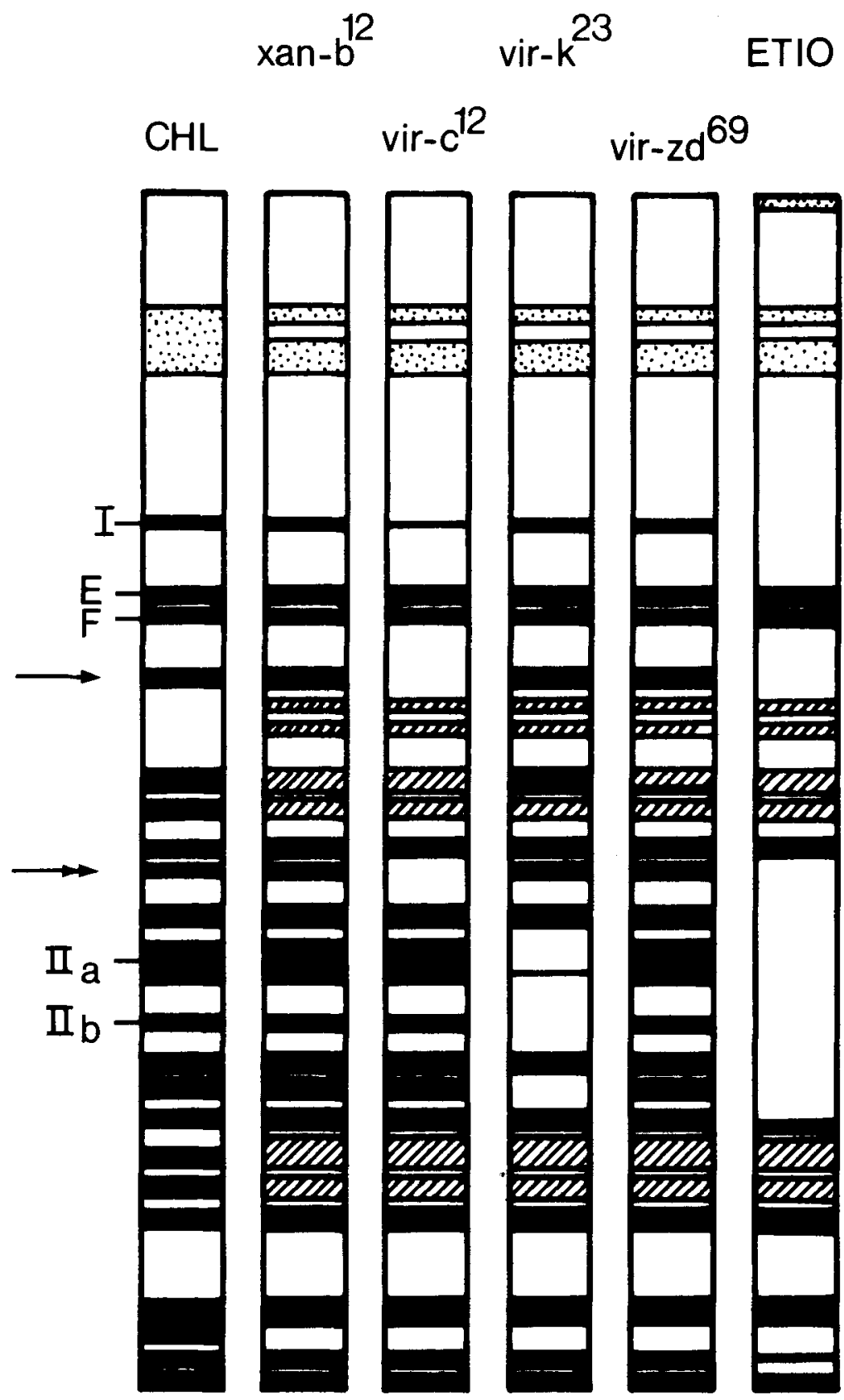

Figure 3. Diagram of electrophoretogram shown in Figure 1 .

band present in chloroplast pattern only or in chloroplast and etioplast patterns

WII band present in etioplast pattern only

犊 aggregates

terns of wild type thylakoid polypeptides and etioplast internal membrane polypeptides.
These two mutants thus appear to contain in their plastid membranes the polypeptides specific to the chloroplast, those specific to the etioplast and those common to the internal membranes of both chloroplasts and etioplasts. The membrane patterns of mutants vir- $c^{12}$ and vir- $k^{23}$ also contain chloroplast specific, etioplast specific and common polypeptides. The membrane pattern of mutant vir-c $c^{12}$ contains all chlo- 


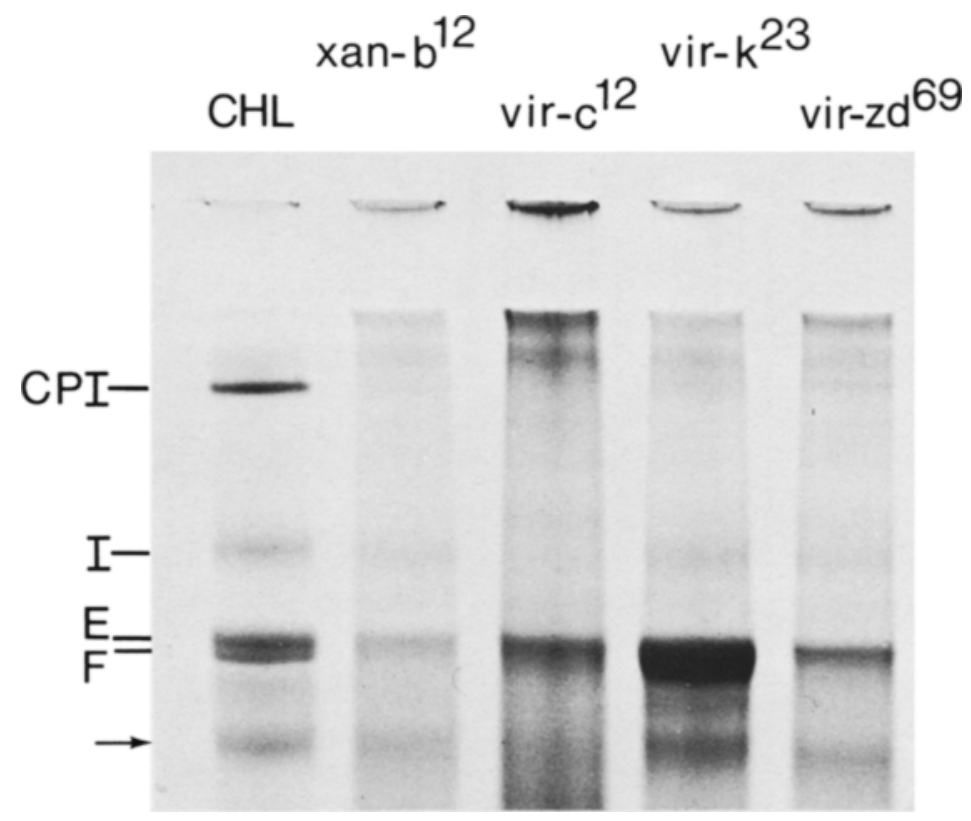

Figure 2. Electrophoretic separation of the high molecular weight polypeptides of thylakoids from wild-type chloroplasts and plastids of four mutants. Membranes disintegrated in their native state with SDS.

roplast specific bands with the exception of two bands. A band with an apparent molecular weight of about 46,000 dalton is not detectable (arrow in Fig. 2). A polypeptide of this size has previously been implicated as a photosystem II reaction center protein $(3,10)$. Another chloroplast specific polypeptide with a somewhat higher electrophoretic mobility (double headed arrow in Fig. 2) is likewise missing or at least strongly reduced in this mutant. A reduction in the intensity of this particular band is observed for vir-z $d^{69}$.

The pattern of vir-k $k^{23}$ is missing three bands. Two of these, II a and II $b$ are the two polypeptides contained in chlorophyll-protein complex II (12). The third is a chloroplast specific polypeptide with a somewhat higher electrophoretic mobility.

\section{DISCUSSION}

The polypeptide patterns of the SDS-solubilized plastid membranes of the four mutants contained no unique bands, $i$. e., apparently no polypeptides with an altered electrophoretic mobility. All bands present in the mutants had counterparts either in wild-type chloroplast thylakoids or etioplast membranes or both. The membrane patterns of the mutants vir- $c^{12}$ and $v i r-k^{23}$ were lacking two and three bands respectively. The simultaneous presence of chloroplast specific and etioplast specific polypeptides in the membrane patterns of the four mutants implies that the internal membranes of the mutant plastids can be viewed as a mixture of etioplast.and chloroplast membranes. A general consequence of the four mutations thus is the continued synthesis of etioplast specific polypeptides in the light. This is associated with retarded plastid development (7) and suggests that the characteristic morphologhy of the membranes in etioplasts and mutant plastids, such as their arrangement in prolamellar bodies, is an expression of the presence of these etioplast specific membrane polypeptides. At this point it cannot be ruled out that the etioplast specific polypeptides represent contaminations from other cellular membranes.

Evidence is accumulating that $\mathrm{CP}$ I contains at least part of the reaction center of photosystem I $(2,19)$. Measurements of photochemical activities during greening of etiolated barley have shown that photosystem I is functioning within the first hour of illumination $(5,15)$. Thus a very rapid induction of synthesis of photosystem I 
protein components after onset of illumination is required, if the components are not present already in the etioplast. If the polypeptide associated with the reaction center of photosystem I indeed corresponds to the band I polypeptide, and if this polypeptide is preformed in etioplast membranes, it could be present and hidden in the aggregated protein regularly found at the top of the gels after electrophoresis of etioplast membranes. The mutants $x a n-b^{12}, v i r-c^{12}, v i r-z d^{69}$ yielded no CP I and vir- $k^{23}$ an unstable CP I upon membrane solubilization. The mutant membranes contained the 69,400 dalton band, which has been identified as the CPI apoprotein $(4,11)$ and have an active photosystem I $(7,9$, 14, 17 and HeNNINGSEN, personal communication). Photosystem I activity of vir-c c $^{12}$ is low on a chlorophyll basis. Interestingly, the 69,400 dalton band is weak in intensity in the membrane polypeptide pattern of this mutant. We interpret the absence or transitory presence of a CP I band in the patterns of the solubilized mutant membranes to be due to a decreased stability of the chlorophyll-protein complex I towards SDS rather than a deficiency of its protein component.

It is generally accepted that CP II does not contain the reaction center protein of photosystem II $(1,3,18,19)$. In previous studies it was shown that the four allelic chlorophyll b-less mutants, chlorina-f 2, -2800, -2808 and -3613 had good photosystem II activity $(16,18)$ in spite of the absence of CP II. In urea-containing gels CP II is resolved into the two protein bands, IIa and IIb, and the membranes of chlorophyll b-less mutants were found to lack IIa but to contain IIb (12). In the present study it is shown that mutant virk- $k^{23}$ is deficient in both polypeptides Ila and IIb, but nevertheless, it exhibits significant Hill activity $(14,17)$. On the other hand, vir-c ${ }^{12}$ and vir-zd ${ }^{69}$ membranes, which are devoid of significant photosystem II activities have both the polypeptides IIa and IIb. From these three observations it is concluded that neither Ila nor IIb can be a reaction center protein for photosystem II.

The location of the reaction center protein of photosystem II in electrophoretic patterns of solubilized thylakoids has been investigated by Chua \& Bennoun (3) with mutants of
Chlamydomonas. They found the absence of a protein with an apparent molecular weight of 47,000 to be correlated with lack of photosystem II activity. According to KLEIN \& VERNON (10) a band corresponding to a polypeptide with a molecular weight of 44,000 is prominent in intensity in electrophoretograms of Triton X-100 membrane particles of spinach enriched in photosystem II activity. If the apparent molecular weight of the reaction center protein of barley is similar to that of spinach and Chlamydomonas, the 46,000 dalton band, marked with an arrow in Figure 1 is a candidate for this protein. This band is absent from the pattern of vir- $c^{12}$, a mutant which is deficient in photosystem II activity. Mutant vir-z $d^{69}$, which also is defective in photosystem II activity does contain the 46,000 dalton band. As mentioned above the pattern of vir- $\mathrm{c}^{12}$ is missing a second chloroplast specific band (double-headed arrow in Figure 1), which is reduced in intensity in vir $z d^{69}$. This band thus might also be important for photosystem II activity. Alternativly the $v i r-z d^{69}$ mutation might cause an amino acid substitution in the 46,000 dalton polypetide and thereby render it inactive. Is has been suggested that CP II is necessary for thylakoid stacking $(1,18)$. We have pointed out $(12)$ that polypeptide Ila is not needed for stacking, as the chlorophyll b-less mutants, which lack this polypeptide, form considerable amounts of grana. The grana deficient mutant $v i r-k^{23}$ investigated here lacks both the polypeptides IIa and IIb. It is therefore not excluded that polypeptide $\mathrm{IIb}$ functions in stacking. Since this mutant lacks an additional chloroplast specific polypeptide with a somewhat higher electrophoretic mobility (cf. Figs. 1,3), it is worth exploring with additional grana deficient mutants if this latter polypeptide is needed for stacking. Further studies are necessary to determine which of the three bands missing in the pattern of SDS-solubilized membranes from mutant vir $-k^{23}$ corresponds to the $\mathrm{J}$ band found affected when the membranes are solubilized in phenol-acetic acid-urea. Mutants $x a n-b^{12}, v i r-c^{12}$ and vir-zd $d^{69}$ are rich in grana and relatively deficient in stroma thylakoids. NIELSEN (13) found the membranes of such mutants deficent in protein $B$. The relative low intensity of the high molecular weight protein I 
band in the three mutants investigated here suggests that the B band corresponds to the protein I of the chlorophyll-protein complex I.

\section{ACKNOWLEDGEMENTS}

We thank Professor D. v. Wettstein for valuable discussions. Miss S. Placing provided skilful technical assistance. Financial support was provided in part by US PHS, National Institutes of Health (GM-22051) and EEC Contract 029-76-ES DK, solar energy program.

\section{REFERENCES}

I. Anderson, J. M.\& R. P. Levine.: Membrane polypeptides of some higher plant chloroplasts. Biochim.Biophys.Acta 333: 378-387 (1974)

2. Bengis, C. \& N. Nelson.: Purification and properties of the photosystem I reaction center from chloroplasts. J.Biol. Chem. 250: 2783-2788 (1975)

3. Chua, N. H. \& P. Bennoun.: Thylakoid membrane polypeptides of Chlamydomonas reinhardtii: Wild-type and mutant strains deficient in photosystem II reaction center. Proc. Nat. Acad. Sci. (US) 72: 2175-2179 (1975)

4. Chua, N. H., K. Matlin \& P. Bennoun.: A chlorophyll-protein complex lacking in photosystem $\mathrm{I}$ mutants of Chlamydomonas reinhardtii. J.Cell Biol, 67: 361-377 (1975)

5. Henningsen, K. W. \& N. K. Boardman.: Development of photochemical activity and the appearance of the high potential form of cytochrome b-559 in greening barley seedlings. Plant Physiol. 51: 1117-1126 (1973)

6. Henningsen, K. W.. N. C. Nielsen \& R. M. Smillie: The effect of nuclear mutations on the assembly of photosynthetic membranes in barley. Portug.Acta Biol.Ser.A XIV 323-344 (1974)

7. Henningsen, K. W., J. E. Boynton, D.von WetTSTEIN \& N. K. Boardman.: Nuclear genes controlling chloroplast development in barley. In: The Biochemistry of Gene Expression in Higher Organisms. J. W. Lee and J. K. Pollak eds. Australian and New Zealand Book Co., Sydney pp. 457-478 (1973)

8. Høyer-Hansen, G., O. Machold \& A. Kahn.: Polypeptide composition of internal membranes from barley etioplasts. Carlsberg Res. Commun. 41: 349-357 (1976)

9. KAHN, A. \& B. CARLSEN.: Evaluation of the photosynthetic capacity of leaves using the oxygen rate electrode. Abstract VII. Internat. Congr. Photobiology. Rome (1976)

10. Klein, S. M. \& L. P. Vernon.: Polypeptide composition of photosynthetic membranes from Chlamydomonas reinhardi and Anabaena variabilis. Plant Physiol. 53: 777-778 (1974)

11. MACHOLD, O.: On the molecular nature of chloroplast thylakoid membranes. Biochim.Biophys.Acta 382: 494-505 (1975)

12. Machold O., A. Meister, H. Sagromsky, G. Høyer-HANSEN \& D. von WetTSTEIN: Composition of photosynthetic membranes of wild-type barley chloroplasts and mutant chloroplasts lacking chlorophyll b. Photosynthetica, in press.

13. NIELSEN, N. C.: Electrophoretic characterization of membrane proteins during chloroplast development in barley. Eur.J.Biochem. 50: 611-623 (1975)

14. Nielsen, N. C., K. W. Henningsen \& R. M. SMILliE.: Chloroplast membrane proteins in wildtype and mutant barley. In: Proc.Third Internat. Congress on Photosynthesis. M. Avron ed., Elsevier Sci.Publ.Co., Amsterdam, pp. 1603-1613 (1974)

15. Plesnicar, M. \& D. S. Bendall: The development of photochemical activities during greening of etiolated barley. In: Proc.II. Internat.Congress on Photosynthesis Research. G. Forti, M. Avron and B. A. Melandri eds., Junk, The Hague, pp. 2367-2373(1971)

16. Sagromsky, H.: Zur physiologischen Bedeutung von Chlorophyll b. Biochem.Physiol. Pflanzen 166: 95-104 (1974)

17. Smillie, R. M., N. C. Nielsen, K. W. HenningSEN \& D. von WETTSTEIN.: Ontogeny and environmental regulation of photochemical activity in chloroplast membranes. In: Proc. Third Internat. Congress on Photosynthesis. M. Avron ed., Elsevier Sci. Publ. Co., Amsterdam, Vol III, pp. $1841-1860(1974)$

18. Thornber, J. P. \& H. R. Highkin: Composition of the photosynthetic apparatus of normal barley leaves and a mutant lacking chlorophyll b. Eur. J. Biochem. 41: 109-116(1974)

19. Thornber, J. P.: Chlorophyll-proteins: Lightharvesting and reaction center components of plants. Ann. Rev. Plant Physiol. 26: 127-158 (1975)

20. Wettstein, D. von \& K. Kristiansen: Stock list for nuclear gene mutants affecting the chloroplast. Barley Genetics Newsletter 3: 113-117 (1973)

21. Suss, K. H.: Identification of chloroplast thylakoid membrane polypeptides: Coupling factor of photophosphorylation $\left(\mathrm{CF}_{1}\right)$ and cytochrome-f. FEBS Letters 70: 191-196 (1976) 